\title{
The Prevalence of Human Immunodeficiency Virus, Hepatitis B Surface Antigen and Hepatitis C Virus among Pregnant Women in Port Harcourt
}

\author{
Elemchukwu Queen ${ }^{1}$,Obeagu Emmanuel Ifeanyi ${ }^{2}$ and \\ Ochei Kingsley Chinedum ${ }^{3}$ \\ ${ }^{I}$ River State College of Health Science and Technology, Port Harcourt. \\ ${ }^{2}$ Diagnostic Laboratory Unit,Deparment of Health Services, Michael Okpara University of \\ Agriculture,Umudike, Abia State, Nigeria. \\ ${ }^{3}$ Department of Medical Laboratory Sciences, Faculty of Basic Medicine, Ambrose Ali University Ekpoma, Edo \\ State, Nigeria.
}

\begin{abstract}
Human immunodeficiency virus (HIV), hepatitis B surface antigen and hepatitis $C$ viral infections are common in Nigeria and are a significant course of mortality and morbidity. This study was undertaken to examine the prevalence of human immunodeficiency virus, hepatitis $B$ surface antigen and hepatitis $C$ antibodies among 500 pregnant women in Port Harcourt. HIV status of subjects was evaluated using an enzyme linked immunosorbert assay (ELISA) of Immunocomb HIV - 1 and 2 kits and hepatitis B surface antigen and hepatitis $C$ antibodies were evaluated using commercially available clinotech HBsAg and HCV test strips. The prevalence of HIV, HBsAg and HCV were $27(5.4 \%), 8(1.6 \%)$ and $30.6 \%)$ respectively. It was recommended that intensive preventive measure be instituted to control the scourge of these viruses.
\end{abstract}

Keywords: HIV, hepatitis B, antigen, antibodies and ELISA.

\section{Introduction}

The human Immunodeficiency Virus (HIV), hepatitis B Virus (HBV) and Hepatitis C virus (HCV) infections have emerged as a global public health problem and a significant cause of mortality and morbidity in Nigeria and many parts of the word (Ejele et al, 2004).

Human Immunodeficiency Virus is a retrovirus belonging to lenti-virus family that kills and damages cells of the body's immune system, and progressively destroys the body's ability to fight infections and cancer thereby leading to Acquired Immune Deficiency Syndrome (AIDS), (Webber and Weiss, 2004). There are two forms of HIV, HIV-1 and HIV 2. Of the two distinct subtypes, HIV-1 is predominant and found throughout the world whereas HIV-2 has been isolated primarily West Africa Countries, such as Guinea Bissau's, Ivory Coast, and Senegal Americas and Western Europe. Both agents are associated with the development of progressive immunologic deterioration. However, epidemiological studies suggest that the incubation period for HIV-2 for the development of disease is longer than for HIV-1. In addition, HIV-2 is not as easily transmitted parentally as HIV-1 (Fauci, 1988).

Hepatitis is on of the most serous risk involved in pregnant women which may lead to chronic active hepatitis, cirrohsis and hepatocellular carcinoma which can be very fatal (Friedrich et al, 1983) and tens of million of people are infected each year with hepatitis and it impact has been the subject of many studies in the last decade. At least three major distinct forms of the disease are now known: Hepatitis A (HA), Hepatitis B (HB) and Hepatitis C (formerly non-A non-B hepatitis). While the viruses, which causes Hepatitis D (Delta Hepatitis), and Hepatitis E (HE) have not been fully characterized and specific laboratory tests are not available for diagnosis. Hepatitis B virus (HBV) infection is a serious health hazard in many countries (Dienstag and Ryan, 1982) with a $10 \%$ prevalence of hepatitis B surface antigen (HBsAg) in some parts of Asia, Africa and the south pacific. During the past years, several putative variants of HBV have been described and some have caused devastating illnesses;

But some patients infected with these variants have no marker of HBV except for HBV-DNA in the liver of serum (Brechot et al., 1985). The hepatitis C virus (HCV) is one of the six viruses (A, B, C, D, E, and $\mathrm{G})$, that together account for the majority cases of viral hepatitis. Hepatitis $\mathrm{C}$ is a blood-borne viral infection that is also responsible for chronic liver disease and has a variety of extra-hepatic manifestation (Di Bisceglie, 1998). Early diagnosis of the disease is by the detection of anti-HCV in the serum of patients using sensitive Enzyme Linked Immunoassays.

At present, 29.2 million people in sub Sahara Africa are infected with HIV, and 3 million are children under the age of 15 years. Thousands of these infected children had acquired this infection vertically from their mothers (crowe et al 2003). A literature survey did not yield any current publication describing the prevalence 
of these viral markers among the population of the Niger Delta. However, information as this will enable effective health care planning; timely institution of preventive measures and also improves the health care outcome of infected individuals.

AIMS

This study therefore, aims at evaluating the prevalence of human immunodeficiency virus, hepatitis B surface antigen and Hepatitis $\mathrm{C}$ virus antibodies among pregnant women in Port Harcourt.

\section{OBJECTIVES}

* To correlate the effect of demographic factors of marital status, age and occupation of these viral matters.

- To provide scientific information in professional and social group on the occurrence of these markers.

\section{Materials And Methods \\ Study Population / Design}

A total of five hundred consecutively recruited pregnant women visiting the antenatal clinic of the Braithwaite Memorial Hospital (BMH), five hundred secondary bed health facility in Port Harcourt, Rivers state, Nigeria were screened for Human immunodeficiency virus (HIV) antibodies, Hepatitis B surface antigen (HbsAg) and hepatitis $\mathrm{C}$ antibodies between June to August 2006 ( a period of three months ). The eligibility criteria include age $\geq 18$, history of pregnancy and willingness to give informed consent after counseling. Exclusion criteria included history of non - pregnancy, previous history of surgery, blood transfusion and age $\geq 18$.Demographic data of the patients, age, marital status and occupation were obtained via an interview admitted questionnaire .

\section{Laboratory analysis \\ Sample collection}

2.5 milliliters $(2.5 \mathrm{ml})$ of whole venous blood were collected from each subject with sarstedt monovette Syringe into a dry tube. The blood was allowed to clot and serum samples were separated by centrifugation and stored as $-2^{0} \mathrm{c}$ until analyzed.

\section{Serological analysis}

Laboratory methods for HIV 1 and 2

each pregnant woman serum sample was screened for antibodies to HIV 1 and 2 using a double Enzyme Linked Immunosorbert Assay (ELISA) of immunicomb HIV - 1 and 2 kits (Orgenics, Israel) and Genscreen HIV 1 and 2 kits (Bio Rad, France). Both are in vitro diagnostics test for the detection of antibodies to HIV, in human serum.

\section{Principles}

It is based on the fact that when an antigen or antibody is coupled to an enzyme the resulting complex retains both immunological and

enzymatic activity so that its presence can be detected by some means

Procedure

Antigen-Antibody Reaction (Row a of the developing Plate)

1) Pipette was use to draw $50 \mu 1$ of the specimen. The foil cover of one well in row $\mathrm{A}$ of the developing plate with the pipette tip was perforated and the specimen was dispensed at bottom of the well. Rapidly refilling and ejecting the solution mixed it pipette tip was discarded.

2) Step one was for the other specimens, including one positive and one negative control supplied with kit. A new well in row A was used.

3) a. The comb was inserted (the printed side facing you) into the wells of row A containing specimens and controls. It was mix several times.

b. The comb in row A was left for 10 minutes with a timer then near the end of 10 minutes the row B was perforated.

c. At the end of 10 minutes, the comb was out of the row A

First wash (Row B) 
4) The comb was inserted into row B. Agitate: Vigorously withdraw and the comb was inserted in the wells for at least 10 seconds to achieve proper washing. Repeated agitation was done several times during the course of 2 minutes: then after 2 minutes, row $\mathrm{C}$ was perforated.

Binding of conjugate (Row C)

5) The comb was inserted into the wells of roll C. mixed several time for 10 minutes as in the step 3B. Then the row $\mathrm{D}$ was perforated.

Incubation in conjugate liquid

6) The comb was inserted into the wells of row $\mathrm{D}$, mixed several times for 2 minutes as in the step 4 . Then the row $\mathrm{E}$ was perforated and after 2 minutes the comb was withdrawn.

Third wash (Row E)

7) The comb was inserted into the wells of row E, and agitated for 2 minutes as in the step 4 . Then the row F was perforated and after 2 minutes the comb was withdrawn.

Color Reaction (Row F)

8) The comb was inserted into the wells of row F, mixed as in the step 3A. After 10 minutes, it was mixed as in step 3B. After 10 minute the comb was withdraw.

Stop Reaction (Row E)

9) The comb inserted again into the wells of row E. After 1 minute the comb was withdraw and air-dried.

Interpretation of Results

If positive, three sports appear on the comb tooth.

If negative, one spot appear on the tooth

If invalid, tow spots appear on the comb tooth.

Laboratory Test for HbsAg

Sera were analyzed for the presence of hepatitis B surface antigen (HbsAg) using commercially available Clinotech HbsAg test strips (Clinotech Diagnostics. Canada). This test is a one step strip for the qualitative detection of HbsAg in serum. All initially positive samples were confirmed using a second generation Trinity Biotech ELISA (Trinity Biotech Plc, Ireland).

Principle

This test is an immune-chromatographic method for the qualitative invitro diagnosis of Hbs Ag.

Procedure

Disposable pipette were use to collect a $\mathrm{ml}$ of the serum and tow-three drops placed on the absorbent pad of the strip.

It was then placed on a support and allowed for 15 minutes to ensure proper and complete migration of the serum after which they were all viewed for reactions and recorded

According to the manufacturer instruction, the test were considered positive, if color bands appears both on the control and test region

Indicating presence of hepatitis $\mathrm{C}$ infections; Negative if only the color bands appears in the control region only, indicating no hepatitis $\mathrm{C}$ infections; and invalid, if no band is visible.

\section{LABORATORY TEST FOR HCV}

Sera were analyzed for the presence of hepatitis C Virus (HCV) antibodies using the commercially available Clinotect HCV test strips (Clinotech Diagnostics, Canada). 
Principles

The test is a one step strip for the qualitative detection of HCV antibodies in serum.

Procedures

Disposable pipette were use to collect a $\mathrm{ml}$ of the serum and two -three drops placed on the absorbent pad of the strip.

It was then placed on a support and allowed for 15 minutes to ensure proper and complete migration of the serum after which they were all viewed for reactions and recorded.

According to the manufacturer instruction, the test were considered positive if color bands appears both on the control and test region

Indicating presence of hepatitis $\mathrm{C}$ infection; negative if only the color bands appears in the control region only indicating no hepatitis $\mathrm{C}$ infections; and invalid, if no band visible.

Statistical analysis

Data were analyzed using a computer database (SPSS version 9: SPSS, Inc, Chicago IL). Differences in prevalence of HIV, HbsAg, and $\mathrm{HCV}$ for demographics (age, marital status and occupation) variables were tested for significance by Chi-square analysis. A $\mathrm{p}$ - value of $<0.05$ was considered significant in all statistical comparisons.

\section{Results}

A total of 500 pregnant women within the ages $<18$ years were screened for human immunodeficiency virus (HIV), Hepatitis B surface antigen (HbsAg) and hepatitis $\mathrm{C}$ virus (HCV) infection. Out of the total number screened, 27 pregnant women representing an overall prevalence of 5.4\% were positive for HIV, 8 pregnant women representing an overall prevalence of $1.6 \%$ were positive for $\mathrm{HBV}$ and 3 pregnant women representing a prevalence $0.6 \%$ were positive for $\mathrm{HCV}$.

Table 1.0 shows the age distribution of pregnant women.

Table 1.0 Age Distribution of Pregnant Women Age Group Number Tested

\begin{tabular}{cc}
\hline & \\
\hline $18-22$ & 205 \\
$23-27$ & 7 \\
$28-32$ & 30 \\
$33-37$ & 63 \\
$38-42$ & 185 \\
& Total $=\mathbf{5 0 0}$
\end{tabular}

Table 2, shows the prevalence of HIV, relation to age. HIV infection was highest within 28-32 yeas age group $4 / 30(13.3 \%)$ followed by $23-27$ years $2 / 17(11.8 \%)$. The lowest prevalence occurred in the $38-42$ years age group $7 / 185(3.8 \%)$ as shown in table 2 .

Table 2: Prevalence of HIV relation to age

\begin{tabular}{llcl}
\hline Age's & Number Number positive for HIV & Percentage (\%) & tested \\
$18-22$ & 205 & 11 & 5.3 \\
\hline $23-27$ & 17 & 2 & 11.8 \\
$28-32$ & 30 & 4 & 13.3 \\
$33-37$ & 63 & 3 & 4.8 \\
$38-42$ & 185 & 7 & 3.8 \\
& Total=500 & 27 & 5.4 \\
\hline
\end{tabular}

Table 3 shows the prevalence of HBV relation to age. HBV infection was highest within 28-32 years age group HBV infection was highest within 28 - 32 years age group 2/30 (6.7\%) followed by 23-27 years age group 1/17 $(5.9 \%)$ as shown in table 3 . No HBV infection within the $33-37$ years age group shown in table 3 . 
Table 3 prevalence of $\mathrm{HBV}$ relation to age

Ages number number positive for HBV percentage $(\%)$

\begin{tabular}{|c|c|c|c|}
\hline $18-22$ & 205 & 3 & 1.5 \\
\hline $23-27$ & 17 & 1 & 5.9 \\
\hline $28-32$ & 30 & 2 & 6.7 \\
\hline $33-37$ & 63 & 0 & 0 \\
\hline \multirow{2}{*}{$38-42$} & 185 & 2 & 1.1 \\
\hline & Total $=500$ & 8 & 1.6 \\
\hline
\end{tabular}

Table 4 shows the incidence of HCV relation to age. HCV infection was highest within 28 -32 years age group 2/30 (6.75) followed by $23-27$ years age group 1/17 (5.9\%) No HCV infection within the 18-22, $33-37$, and 3832 years age group as shown in table 4 co-infection of HIV, HBV and HCV occurred with 28-32 years age group $4 / 30(13.3 \%)$ and $2 / 30(6.7 \%)$ as shown in table 2,3 , and 4 .

Table 4 prevalence of $\mathrm{HCV}$ relation to age

\begin{tabular}{cccc} 
Age's & Number & Number positive for HCV & Percentage $(\%)$ \\
\hline & Tested & & 0 \\
$18-22$ & 205 & 0 & 5.9 \\
$23-27$ & 17 & 1 & 6.7 \\
$28-32$ & 30 & 2 & 0 \\
$33-37$ & 63 & 0 & 0 \\
$38-42$ & 185 & 0 & 0.6
\end{tabular}

Table 5 shows the distribution of HIV positivity in pregnant women based on occupational groups. The highest prevalence occurred with the applicants $6 / 55$ (10.9\%). The lowest prevalence for HIV infection occurred among the farmers.

Table 5 distribution of HIV positivity in pregnant women based on occupation groups

\begin{tabular}{llll}
\hline $\begin{array}{l}\text { Occupational } \\
\text { Group }\end{array}$ & $\begin{array}{l}\text { Total No. } \\
\text { Screened }\end{array}$ & $\begin{array}{l}\text { Number of HIV } \\
\text { Positivity }\end{array}$ & $\begin{array}{c}\text { \%HV } \\
\text { positivity }\end{array}$ \\
\hline & & & 10.9 \\
Applicants & 55 & 6 & 5.3 \\
Civil servants & 95 & 5 & 4.4 \\
Farmers & 180 & 8 & 5 \\
Oil workers & 40 & 2 & 5.4 \\
Students & 130 & 7 & \\
\hline
\end{tabular}

Table 6 shows the distribution of HBV positivity in pregnant women based on occupational groups. The highest prevalence occurred with the applicants $3 / 55$ (5.4\%). The lowest prevalence for HBV infection occurred among the students.

Table 6 distribution of HBV positivity in pregnant women based on occupational groups

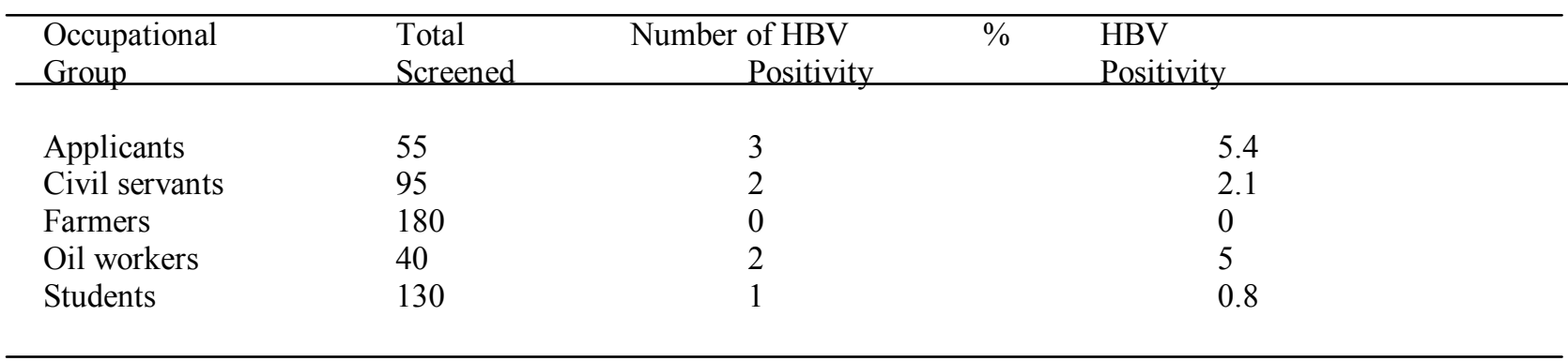


Table 7 shows the distribution of HCV positivity in pregnant women based on occupational groups. The highest prevalence occurred with the applicants $2 / 55(3.6 \%)$. The lowest prevalence occurred among the students.

Table 7: distribution of HCV positivity in pregnant women based on occupation groups

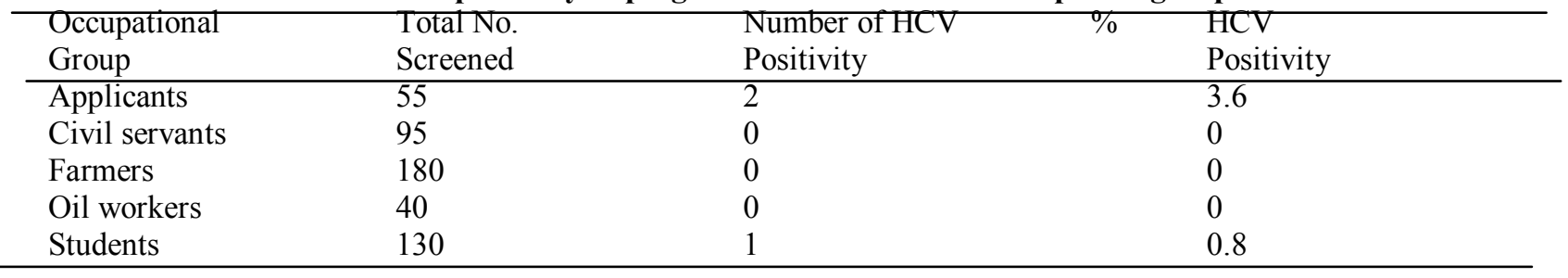

Table 8 shows the distribution of HIV positivity in pregnant women based on marital status. The highest prevalence occurred in the widow/separated 10/122 (8.1\%). Married show the lowest prevalence.

Table 8 distribution of HIV positivity in pregnant women based on marital status

\begin{tabular}{llll}
\hline Marital status & Number & Number of HIV & \% of HIV \\
\hline & Screened & Positive & Positive \\
Married & 378 & 17 & 4.5 \\
Widow/separated & 122 & 10 & 8.1 \\
\hline
\end{tabular}

Table 9 distribution of HBV positivity in pregnant women based on marital status

\begin{tabular}{lccl}
\hline Marital status & Number & Number of HBV & \% HBV Positive \\
\hline Married & 378 & 3 & 0.8 \\
Widow/separated & 122 & 5 & 4.1 \\
\hline
\end{tabular}

Table 10 shows the distribution of HCV positivity in pregnant women based on marital status. The highest prevalence occurred in the widow/separation 2/122 (1.6\%). Married how the lowest prevalence 1/378 (0.2\%)

Table 10: distribution of HCV positivity in pregnant women based on marital status

\begin{tabular}{lccc}
\hline Marital status & Number & Number of HBV & \% HBV Positive \\
\hline Married & 378 & 1 & 0.2 \\
Widow/separation & 122 & 2 & 1.6 \\
\hline
\end{tabular}

\section{Discussion}

There is a gap of information concerning the prevalence of viral markers among pregnant women in Nigerian population. However, information as this will enable effective health care planning; timely institution of preventive measures and also improves the health care outcome of infected individuals.

This study therefore, aims at evaluation the prevalence of human immunodeficiency virus, hepatitis B surface antigen and hepatitis $\mathrm{C}$ virus antibodies among pregnant women in Port Harcourt. This was achieved by correlating the effect of demographic factors of marital status, age and occupation of these viral matters and to provide scientific information in professional and social group on the occurrence of these markers.

In this study we observed that, HIV, HBV, and HCV prevalence among pregnant women is $54 \%, 1.6 \%$ and $0.6 \%$ respectively. These findings in this study are in agreement with Ejele et al (2005), and also with ward et al (2000). The value obtained in this study is however less than that reported in the North Eastern part of Nigeria by Baba et al (2000), Sirisena et al, (2000) Nigeria; Amed et al, (1998), Bradley et al (2000) and Ejele et al, (2004). The prevalence of HIV, HBV and HCV in pregnant women in this study is however higher than that obtained by pamzo et al, (2000); Obi et al, (2004), Hutchinson et al (2000), and Halim et al, (2000), There seems to be a significant association between HIV, HBV and HCV. This observation have been accounted for by the fact-that both infections have common modes of transmission, which is predominantly high risk sexual behaviour Homosexual and heterosexually promiscuity, intravenous drug user and use of infected or unscreened blood and blood products and vertical transmission from mother to child.

The prevalence of HIV, HBV, and HCV infection in pregnant women was found in this study to be higher among widow/separated. This observation is in agreement with Ejele et al, (2004). This observation may have been accounted for the fact that the widowed / separated are more likely to maintain multiple sex partners or be involved in high risk behaviors that makes them vulnerable to infection with $\mathrm{HIV}, \mathrm{HBV}$ and $\mathrm{HCV}$.

Among the occupational group, the applicant and students recorded the highest rate of $\mathrm{c} 0$-infection with HIV, HBV and HCV. This finding is a agreement with Ejele et al, (2004). These may be due to the fact that poverty resulting from unemployment among applicant. 


\section{Conclusion and Recommendations}

The prevalence of HIV, HBsAg and HCV antibodies among pregnant women in port Harcourt, Rivers State had established. The existences of the viral markers (especially among this group) are a pointer for additional call to duty for all stakeholders; the need to galvanized effort to minimize their incidence, and provide appropriate intervention for their management.

The following recommendations are warranted:

- We recommend that result obtained in this study be used as a working data on the prevalence of HIV, HBV and HCV among pregnant women in port Harcourt, Rivers State, Nigeria and that immediate interventional measures be employed by government and other health agencies with the hope of prioritizing preventive measurers such as health education of the general population and discouraging cultural practices that promotes transmission of $\mathrm{HIV}, \mathrm{HBV}$ and $\mathrm{HCV}$; transfusion of unscreened blood and blood products; injecting with unsterilized needles, sharing of blades and sharp objects used for scarification, barbing, ear piercing and circumcision.

* We suggest that the graduates should be given employment and the non-graduates should be encouraged to learn some skills through the skill acquisition programme.

- All HIV infected pregnant women in Port Harcourt, Rivers State without HBV and HCV co-infection should be immunized against viral hepatitis B and C.

* The cost of vaccines should be subsidized by government and made readily available for the general population.

* Additional studies are advocate to study the epidemiology of these viruses in our setting.

\section{References}

[1]. Ahmed S.D., Cuevas L.E., Brabin B.J., Kazemb P., (1998). Sero-prevalence of Hepatitis B, C and HIV in makwian pregnant women. Journal of Infectious Diseases 37: 248-51.

[2]. Alter. H.J and Holland. P.V (1997): Post-transfusion hepatitis after exclusion of commercial and HBsAg positive donors Annal of internal medicine 77: 691

[3]. Alte,r M.J and Sampliner, R.E (2000): Hepatitis C. New England journal of Medicine 321:1538-1540.

[4]. Almeda, J. and Waterson, A.P (1969): Immune complex in hepatitis lancet 2:933.

[5]. Baba, M.M., GasHau, W., Hassan, A.W (2000): Dtection of hepatitis B Surface antigenemia in patients with and without the manifestation of aids in Maiduguri, Nigeria. Postgraduate Medical Journal 5:125-127.

[6]. Blumberg, B.S, London, W.T (1980): HBV and PHCC: In-Essex M., Todora G., HausaH., Viruses and naturally occurring cancers. Cold spring Habour conference on cell proliferation. Cold spring Habour Press. New York. Pp 401-421.Blumberg, B.S., Alter, H.J., Bisnich, S.A (1965): Antigen in Leukaemia Sera, Journal of American Medical Association 108; 247.

[7]. Boxall, E.H., Flewitt, T.H., Patton, A. (1976): HBsAg and Cirrhosis in Iraq. Gut 17:119.

[8]. Bradley, D.W. Hollinger, F.B. Hornbeck, C.L. Maynard, J.E (2000): Isolation and characterization of hay. American Journal of Clinical Pathology 65:876

[9]. Brechot. C. Degos, F., Lugassy, c. (1985) HBV DNA in patient with chronic liver disease and negative test for HBsAg. New England Journal of Medicine 312:270-276.

[10]. Dane. D.S Cameron. C.H,. Briggs, M. (1970): Virus-like particles in serum of patients with Australia-antigen associated hepatits lancet 1:698.

[11]. Deinshardt, F. and Gust, D.I. (1982): Viral hepatitis. Bulletin of WHO 60:661-691.

[12]. Department of health (2000): Hepatitis C strategy for England. London.

[13]. Di Bisceglie. A.M. (1998): Seminar HCV. The Lancet 351:351-354

[14]. Dientag, J.L and Ryan D.M (1982): Occupational exposure to HBV in hospital personnel: infection and immunization. American Journal of Epidemiology 115:26-39

[15]. Donahue, J.G., Munoz, Z., Ness, P.M. (1992): declining risk of post- transfusion hepatitis C Virus Infection. Nigeria England Journal of Medicine; 327: 369-73

[16]. Eleje, O.A., Osaro, E., Chijioke, A.N. (2005): The prevalence of Hepatitis C Antibodies in patients with HIV Infection in the Niger Delta of Nigeria. Highland Medical Research Jaurnal 1.

[17]. Feitelson, M.A (1999): B virus in hepato-carcinogensis. Journal of Cell Physiology. 18:188-202.Fridrick, D., Jachen, A., Fakhry, A. (1983): Virus Hepatitis World Health Organization Chronicles 37:203-207

[18]. Fauci, .A.S (1988): The human immunodeficiency virus infectivity and mechanisms of pathogenesis. Science 239:617-72.

[19]. Gibb, D.M. Goodall, RL. Dunn, D.T. (2000): Mother to child transmission of hepatitis C virus: evidence for preventable peripatum transmission. Lancet 356:904-7

[20]. Goldberg, D., Taylor, A., Hutchinson, S. (2000): Hepatitis C. Infection among injecting drug users in Scotland stemming the Flow, Scotland Medical Journal 45:131-2.

[21]. Hadler, S.C Judson, F.N. O'malley, P.M. (2000): Outcome of hepatitis B virus infection in homosexual men and its relation to prior human immunodeficiency virus infection. Journal of infectious diseases 63:454-459.

[22]. Hadzic, N. (2000): Hepatitis C in pregnancy. Achieve of disease of children and neonatal edition 84:201-4.

[23]. Halim, N.K,. Offor, E., Ajagi, O.I. (2000): Epidemiological study of the sero-prevalence of hepatitis B surface antigen (HBsAg) and HIV-1 in blodd donors. Nigeria journal of clinical practice 2:42-45.

[24]. Hutchison, S.J. Goldberg, D.J., King, M., Cameron, S.O., show, L.E. (2004): Hepatitis C virus among childbearing women in Scotland prevalence, deprivation, and diagnosis. British medical Journal 53:593-598.

[25]. Iwarson, S., Magnus, I., Lindhoml, A., Lundin, P. (1973): Subtypes of HBsAg in blood donors and post-transfusion hepatitis clinical and epidemiology aspect. british Medical Journal 1:84.

[26]. Jones, M. (1999): Hepatitis C Infection in children. Nigeria England Journal of Medicine 341:912-3. 
[27]. Krugman, S., Hoofinagle, J.H., Gerety, R.I., Kaplan, P.M., Gerin J.L (1974): viral hepatitis type B: DNA polymerase activity and antibody to HBsAg. New England journal of medicine 290: 1331-1335.

[28]. Le Bouier, G.L. (1972): Sub specificities of the Anstralia antigen complex. American Journal of Diseases 123:420.

[29]. Lebovices, E., Divorkin, B.M., Heier, S.K., Rosenthal, W.S. (1988): The hepato-billary manifestations of human immunodeficiency virus infection. American Journal of Gastroenterology 83:1-7.

[30]. Lee, M., Lee, M., Lee, S.K. (2002): Expression of Th 1 and Th 2 type cytokines responding to HBsAg and HbxAg in chronic hepatitis B patients. Journal of Korean Medical Science 14:175-181.

[31]. Lee, W.M. (1997). Hepatitis B virus Infection: Nigeria England Journal of Medicine. 337:1733-1745.

[32]. Martnez, J.L., Juarez, M.O., Dantes, H.G. (2003): Sero-prevalence of Hepatitis B in pregnant women in mexico salud pubican mexico 45,3

[33]. Obi, C.L., Angiwo, C.E., Nnatu, S.N., Agbonalahor, D.E., Esumeh F.I. Karpas., A. (2004); a comparism of human immunodeficiency virus (HIV) seropositivity and hepatitis B surface antigeamia ( $\mathrm{HBsHg}$ ): among the same the same group of apparently healthy pregnant women. Lagos, preliminary report.

[34]. Obiaya, M.O., Ebohon, P.A (1982): Blood transfusing hazards is Benin city, Nigeria: Hepatitis B Antigenamia. Nigeria medical Journal,12:251-254.

[35]. Panizo, D.A, Martiez de, A.V., panizo, C. (1994) Seroprevalence of hepatitis B virus markers in pregnant women, Review of clinical Experimental. 1:891-6.

[36]. Scott, G.R. (1999): The Sexual transmission of Hepatitis C virus International Journal of Sexual Transmission Disease, AIDS 6:1-3.

[37]. Seriano, V., Geircia, S.J., Valencia, E. (2000): Impact of chronic Liver disease due to hepatitis virus as a cause of hospital admission and death in HIV-infected drug user. European journal of epidemiology 15:1-4.

[38]. Sirrisena, N.D., Njoku, M.D., Idoko, J.A. (2000): Hepatitis B Surface antigenaemia in patients with human immunodeficiency virus-1 (HIV-1) infection in Jos, Nigeria. Medical practice 41:18-20.

[39]. Stevens, C.E., Taylor, P.E., M. (1997): Yeast recombinant hepatitis B vaccine; efficacy with hepatitis B immune globulin in prevention of perinatal hepatitis B virus transmission. Journal of America Medical Association 257:2612-6.

[40]. Steven, C.E., Beasly, R.P., Tsui, J. (1975): vertical transmission of HBsAg in Taiwani. New England of Medicine 292:771 -774.

[41]. Summary finding. (2001): HIV/Syphilis sentinel sero-prevalence survey in Nigeria. Information for policy makers 30-50.

[42]. Surya, I.G., Komia, K., Suwardewa, T.G. (2005) Serological Markers of Hepatitis B, C, and E viruses and human immunodeficiency virus Type-1 infections in pregnant women in Bali, Indonesia. Journal of Medical Virology 57:499-503.

[43]. Thomas, S.L., Newell, M.L.; peckham, C.S.; (2000): A Review of HepatitisC. Virus (HCV) vertical transmission risks of transmission to infants born to mothers with and without HCV vriaemia or human immunodeficiency virus, international Journal of Epidemiology; 27:108-17.

[44]. Toy, P.T., Tong, M.J., Stevens, C.E. (1999): perinatal hepatitis B virus transmission in the United states; prevention by passiveactive immunization, Journal of American Medical Association 253:1740-5.

[45]. Ward, C., Tudor, G., Williams, G., cotzias, T., Hargreaves, S., Regan, L., Foster, G.R. (2000): prevalence of hepatitis c among pregnant women attending an inner London obstetric department: uptake and acceptability of named antentatal testing. Gut 47:77280.

[46]. Webber, J.N. and Weiss. (2000): virology of human immunodeficiency virus. British medical Bulletin pp. 10-13.

[47]. Wejstal, (1999): transmission of hepatitis C virus journal of hepatitis 31:92-5.

[48]. Willey-liss, A.J. (2005): serological markers of hepatitis B,C and E viruses and human immunodeficiency virus type -1 infection in pregnant women. Science 244:359-362.

[49]. World Health Organization Consutation Group (1999): Global Surveillance and control of Hepatitis C virus. Journal of Viral Hepatitis, 6:35-47.

[50]. Zuckerman, A.J., C.R., Taylor, P.E. (1975): Diagnosis of hepatitis, virus hepatitis, Bulletin of New York Academic of Medicine 2:36-36. 